\title{
PEDAGOGIA DO ESPORTE E O REFERENCIAL HISTÓRICO-CULTURAL: INTERLOCUÇÃO ENTRE TEORIA E PRÁTICA.
}

\author{
Gisele Viola Machado \\ Universidade Estadual de Campinas , Campinas, São Paulo, Brasil \\ Larissa Rafaela Galatti \\ Universidade Estadual de Campinas , Campinas, São Paulo, Brasil \\ Roberto Rodrigues Paes \\ Universidade Estadual de Campinas , Campinas, São Paulo, Brasil
}

\begin{abstract}
Resumo
A Pedagogia do Esporte aborda o mesmo enquanto fenômeno sociocultural, e seu trato pedagógico é defendido a partir de três referenciais: técnico-tático, socioeducativo e histórico-cultural, sendo este último a ênfase do presente estudo. Assim, apresentamos resultados e análise de pesquisa de campo com uma equipe feminina de basquetebol vinculada à Federação Paulista de Basquetebol, a fim de evidenciar o mau trato dos aspectos histórico-culturais do esporte nas aulas e treinamentos esportivos. A seguir, sinalizamos procedimentos pedagógicos que possam contribuir para a melhor abordagem desse referencial, que pode fomentar a cultura esportiva do atleta, do aluno e do praticante informal.

Palavras chave: Esporte. Pedagogia do Esporte. Cultura Esportiva. Jogos Esportivos Coletivos. Basquetebol.
\end{abstract}

\section{Introdução}

O esporte é um fenômeno sociocultural de natureza educacional, característica que é evidenciada quando a prática esportiva recebe um tratamento pedagógico adequado, podendo contribuir de maneira significativa para a formação cidadã. Reverdito e Scaglia (2009, p.37) afirmam que: "o ensinar pelo esporte deve estar comprometido com a autonomia do ser humano, com a formação de cidadãos críticos". 
Para tanto, uma das maneiras de contribuir com esta formação é proporcionar, através do processo de ensino, vivência e aprendizagem das modalidades esportivas, conteúdos centrados nos referenciais técnico-táticos e socioeducativos, apresentados por Paes (1996), englobando aspectos técnicos, táticos, motores, físicos, bem como valores e modos de comportamento, respectivamente.

Além destes, este estudo reforça a necessidade de inserção de um terceiro referencial na prática pedagógica do esporte, com a finalidade de incluir intencionalmente os aspectos histórico-culturais que as modalidades carregam, como a história, regras e suas alterações, jogadores importantes para o cenário nacional, atualidades, entre outros saberes necessários para a compreensão das diferentes modalidades. Essa é uma prerrogativa importante para o convívio com o esporte como espectador ou praticante, em especial no Brasil, que vive a chamada "década do esporte", sediando megaeventos que carecem de um público melhor conhecedor deste fenômeno (PAES; GALATTI, 2012, 2013; MACHADO, 2012).

Portanto, neste estudo, trataremos a Pedagogia do Esporte balizada em três referenciais: o técnico-tático, o socioeducativo e o histórico-cultural. Pois, ao pensar uma Pedagogia do Esporte que se direcione nos caminhos da formação da cidadania e da autonomia dos alunos, é fundamental a inclusão deste terceiro referencial, que reforça os outros dois já existentes, direcionando processos de ensino, vivência e aprendizagem de modalidades esportivas que respeitam a integralidade do esporte e, sobretudo, de quem o pratica.

Para isso, o presente estudo parte da revisão de literatura para consolidar este terceiro pilar, tendo por base autores da Pedagogia do Esporte, em especial aqueles relacionados aos Jogos Esportivos Coletivos. A seguir, houve uma pesquisa de campo a fim de verificar o conhecimento deste referencial na modalidade basquetebol da equipe feminina da cidade de Taubaté (SP), participante de competições da Federação Paulista de Basquetebol. A pesquisa foi realizada por meio de entrevista na técnica do Focus Group, para ilustrar o hiato no trato com o referencial histórico-cultural, presente em diferentes cenários da prática esportiva. Por fim, apresentamos possibilidades didático-pedagógicas de inserção deste referencial nas práticas esportivas no contexto não formal.

\section{Métodos}

O presente estudo parte de uma breve revisão bibliográfica acerca da Pedagogia do Esporte e os referenciais sugeridos para o trato com o mesmo:

Pensar a Prática, Goiânia, v. 17, n. 2, p. 414-430, jan./mar. 2014 415 
o técnico-tático, o socioeducativo e o histórico-cultural, sendo este terceiro o eixo central da pesquisa.

Na sequência, a fim de fomentar a discussão da relevância do trato com o referencial histórico-cultural no contexto da educação não formal, apresentamos investigação com 13 atletas da equipe feminina de Basquetebol da cidade de Taubaté-SP, objetivando identificar quais os conhecimentos das jogadoras acerca do histórico, evolução, regras e personalidades da modalidade que praticam.

De característica qualitativa, a pesquisa de campo se deu por meio de entrevista semiestruturada, através da técnica do Focus Group, que segundo Morgan (1996), é utilizada para coletar dados através da interação de um grupo, conforme tema selecionado e direcionado pelo pesquisador. $\mathrm{O}$ autor sinaliza os pontos fortes da técnica, entre eles: os grupos são fáceis de conduzir; não necessita de apoio financeiro; mesmo que o pesquisador seja principiante ele poderá obter muitas informações, pois o grupo permite que ele explore tópicos e as hipóteses gerais, viabilizando a interação dos mesmos com o interesse do pesquisador.

A entrevista foi realizada no mês de Abril de 2011, em mesmo local de treinamento das atletas, sem interferências e com a ausência de qualquer componente da comissão técnica. Para a coleta dos dados da entrevista foi utilizada uma filmadora, SONY DCR-SR47, colocada em um ponto fixo de modo a captar a imagem e a fala de todas do grupo.

O roteiro de entrevista foi composto de 11 questões relativas ao contexto geral (histórico, evolução e regras) e ao contexto nacional (atletas e títulos mais representativos) do basquetebol, além de questões relacionadas ao estímulo desse conhecimento ao longo do processo de treinamento.

A análise dos dados, como sugere Leitão (2003), foi feita em duas etapas: análise qualitativa, que se baseia na própria discussão e citações do grupo, e a análise de conteúdos, gerando uma descrição qualitativa dos dados.

\section{Pedagogia do Esporte e seus referenciais}

Paes (1996) e Paes e Balbino (2005) apontam que, para a formação do indivíduo, as aulas e treinos de esporte devem ser pautados em dois referenciais: o técnico-tático - que deve buscar responder a três questões: O que ensinar? Quando ensinar? Como ensinar? - e o socioeducativo, relacionado ao processo educacional do ser humano, visando à formação integral de quem joga. A partir dos autores, propomos a inclusão de um terceiro referencial, o histórico-cultural, que aborda as questões referentes à trajetória de cada modalidade. Cabe tratarmos de cada um desses referenciais.

Pensar a Prática, Goiânia, v. 17, n. 2, p. 414-430, jan./mar. 2014 416 
É importante ressaltar que os estudos dentro da Pedagogia do Esporte com os dois referenciais primeiros apresentados surgiram na década de 90, através da pesquisa de Paes (1996). O autor já se preocupava em abordar a Pedagogia do Esporte centrada não somente na formação técnica e tática, mas também na formação cidadã, ao inserir neste contexto esportivo o trato de valores e modos de comportamento.

\section{Referencial técnico-tático:}

O referencial técnico-tático diz respeito à organização e sistematização pedagógica das modalidades esportivas para a vivência e prática das mesmas, além da escolha metodológica para sua aplicação. Diversos autores da literatura de ensino e aprendizagem esportiva tratam deste referencial, sendo destacados neste estudo propostas que enfocam os Jogos Esportivos Coletivos (JECs).

Quanto à organização e sistematização de conteúdos, no contexto escolar, Paes (1996) aborda quatro JECs - voleibol, basquetebol, futebol e handebol - para o Ensino Fundamental, definindo a divisão de conteúdos por meio de fases do ensino. São elas: Pré-Iniciação ( $1^{\mathrm{a}}$ e $2^{\mathrm{a}}$ séries), com os conteúdos de domínio de corpo e manipulação de bola; Iniciação I ( $3^{\mathrm{a}}$ e $4^{\mathrm{a}}$ séries), com os conteúdos: passe, recepção e drible; Iniciação II ( $5^{\mathrm{a}}$ e $6^{\mathrm{a}}$ séries $)$, sendo os conteúdos sugeridos: finalização e fundamentos específicos das modalidades em pauta; e Iniciação III ( $7^{\mathrm{a}}$ e $8^{\mathrm{a}}$ séries), com os conteúdos: situação de jogo, transição e sistemas ofensivos e defensivos.

Em perspectiva mais ampla, Greco e Benda (2007) abordam o tratamento do esporte com uma proposta pedagógica intitulada de Iniciação Esportiva Universal, apresentando nove fases de acordo com a idade dos praticantes, chamada de Estrutura Temporal.

Bayer (1994) apresenta semelhança entre as modalidades coletivas, estruturando sua proposta pedagógica a partir de características comuns, princípios operacionais e regras de ação válidas para todas as modalidades, sinalizando para uma pedagogia das intenções.

Quanto às possibilidades metodológicas para a aplicação dos conteúdos, Dietrich (1984) já destacava dois princípios que sustentam as diferentes propostas: (1) o analítico-sintético, que é estruturado em cursos de exercícios com ênfase na repetição de tarefas para o aprimoramento técnico, na expectativa de posterior melhora no jogo formal, dicotomizando treinamento técnico e tático; e (2) princípio global-funcional, com base em cursos de jogos, partindo dos menos complexos para os mais elaborados, ofertando ao praticante situações-problema diversas, tal qual o jogo formal, integrando treinamento tático e tático. 
Em relação ao primeiro princípio destacamos o tradicional tecnicismo, enquanto no segundo princípio observamos nas últimas três décadas uma pulverização de novas propostas, como as apresentadas na obra de Bayer (1979); Banker e Thorper (1986); Graça e Oliveira (1995); Paes (1996); Greco et al (1998); Siedentorp (2003), Reverdito e Scaglia (2010), entre outros.

\section{Referencial socioeducativo}

Paes e Balbino (2009, p. 75), ao descreverem os referenciais da Pedagogia do Esporte, afirmaram que: "restringir a Pedagogia do Esporte somente às questões metodológicas significa limitar as possibilidades do esporte, reduzindo-o a uma prática simplista e descontextualizada do esporte contemporâneo". Corroborando com os autores, Galatti (2006) afirma que, por ser o esporte um fenômeno de múltiplas possibilidades, promove não somente a aprendizagem das questões técnicas e táticas, mas também pode promover e discutir valores. $\mathrm{O}$ trato com valores e modos de comportamento no processo de ensino, vivência, aprendizagem e treinamento esportivo é que diferentes autores denominam como referencial socioeducativo.

Santana (2005) destaca a natureza educativa do esporte, apontando para a importância de aulas que estimulem o desenvolvimento da autonomia do aluno e não se restrinjam somente aos aspectos motores. Greco e Benda (2007), por sua vez, enfatizam o papel do professor em estimular o aluno a tomar suas próprias decisões em situações de jogo, com a base pautada pelos princípios éticos, educativos, formativos e de importância ao desenvolvimento do aluno, tratando-o como um todo e não como soma das partes.

Reverdito e Scaglia (2009, p. 131) fortalecem a expansão das contribuições do esporte na formação humana, ao afirmar que a Pedagogia do Esporte deve "permitir ao homem aprender a viver, a viver em sociedade, a compartilhar sua humanidade".

Em estudo específico sobre as contribuições socioeducativas do esporte, Hirama (2008) busca responder questões relacionadas com a Pedagogia do Esporte e a minimização dos problemas enfrentados pelos jovens em favelas, tais como:

(...) baixa auto-estima, a falta de pertencimento a um grupo que lhe dê expectativas de evolução e desenvolvimento, as poucas opções para o distanciamento do tráfico, a exclusão de ambientes culturais e educacionais de qualidade, a educação formal de má qualidade, entre diversos outros. (p. 44)

Pensar a Prática, Goiânia, v. 17, n. 2, p. 414-430, jan./mar. 2014 418 
Para tanto, o autor preocupa-se em adequar procedimentos pedagógicos que deem conta de diminuir tais flagelos sofridos por esta população de jovens, propondo ênfase nos Quatro Pilares da Educação: Aprender, Aprender a Fazer, Aprender a Ser e Aprender a Conviver (DELORS, 2001).

Portanto, no viés de novas tendências da Pedagogia do Esporte, diversos autores compartilham que o ensinar o esporte deve estar balizado com a formação de cidadãos críticos, autônomos, capazes de produzir, reproduzir e ressignificar a cultura esportiva. Para tanto, é pertinente a prerrogativa de Freire (2002) de: educar pelo esporte, ensinar o esporte para todos, ensiná-lo bem, ensinar mais do que ele próprio e ensinar a gostar de esporte.

Ensinar o esporte e ensinar a gostar do esporte passam por conhecer sua origem, sua história, evolução, personagens e fatos marcantes, o que nos remete à inserção do terceiro pilar dentre os referenciais da Pedagogia do Esporte: o histórico-cultural.

\section{Referencial histórico-cultural}

O trato com o referencial técnico-tático é recorrente nas obras de Educação Física e esporte. No entanto, observamos nas novas tendências em Pedagogia do Esporte, preocupação também com o referencial socioeducativo. Mas, se o tratamento pedagógico adequado ao esporte busca dar conta de uma formação voltada à cidadania e à crítica dos alunos, como contribuir para esta formação se os elementos históricos e culturais são privados aos mesmos? Como influenciar a apreciação do esporte, o gosto pelo esporte, a ressignificação de tais práticas se o aluno não conhece a trajetória, a evolução, o surgimento das modalidades esportivas, de eventos esportivos internacionais, se não há compreensão sobre o contexto das regras, sobre a influência da mídia?

Para acenar respostas a estes questionamentos é que apresentamos o referencial histórico-cultural, tema aventado por Galatti (2006), ao tratar dos aspectos históricos na proposição de livro didático para o ensino não formal; por Hirama (2008), ao sugerir uma pedagogia voltada ao "saber", quando aponta os Quatro Pilares da Educação; e por Machado (2012), ao verificar a aplicação de tais conteúdos nas aulas esportivas de um projeto social.

Este referencial objetiva resgatar no trabalho do pedagogo do esporte estas questões que fazem parte da história de cada cidadão, já que o esporte é um patrimônio cultural da humanidade construído e ressignificado constantemente pela sociedade, e que precisa ser compreendido pela mesma.

Assim, para o esporte ser um dos contribuintes para a formação integral do aluno-jogador, é fundamental que as aulas/treinamentos sejam pautadas de

Pensar a Prática, Goiânia, v. 17, n. 2, p. 414-430, jan./mar. 2014 419 
forma equilibrada nos três referenciais: no metodológico, no socioeducativo e, como propomos, no histórico-cultural.

Desta forma, o aluno ou o atleta tem condições de percorrer seu caminho ligado ao esporte de maneiras distintas, conforme interesses pessoais e possibilidades, podendo atuar como: atleta profissional; treinador / professor de Educação Física; comentarista / jornalista esportivo; espectador; praticante de esporte como lazer; árbitro; investidor; dentre outras opções em que a formação estará pautada tanto na parte físico-motora, quanto na afetivo-social e também na histórico-cultural.

\section{Pesquisa de campo: perfil das entrevistadas, resultados e discussões}

Dada a defesa deste artigo à inclusão de um referencial histórico-cultural no trato com o esporte, estabelecemos pesquisa de campo a fim de verificar, em amostra restrita, o conhecimento e interesse de um grupo de atletas quanto ao mesmo, sendo investigada a equipe de basquetebol feminino da cidade de Taubaté - SP. Essa equipe foi selecionada por estar vinculada à Federação Paulista de Basquetebol, participando regularmente das competições da entidade nas categorias de base, mas sem equipe adulta profissional.

A pesquisa foi aprovada pelo Comitê de Ética da Universidade de Taubaté, (UNITAU) sob o protocolo CEP/UNITAU 154/11 de 20 de maio de 2011.

\section{Perfil das entrevistadas}

O grupo de atletas entrevistadas foi composto por 13 jogadoras da modalidade de basquetebol da cidade de Taubaté - SP, que treinam de $2^{\mathrm{a}}$ a $6^{\mathrm{a}}$ feira, das 18:00h às 20:00h, participando de competições em nível regional (Liga do Cone Leste Paulista) e Estadual (Federação Paulista de Basquetebol), nas categorias sub-13, sub-15 e sub-19.

Quanto ao vínculo federativo, conforme verificado junto ao site da Federação Paulista de Basquetebol (FPB), 11 das atletas (84\%) são federadas e duas (16\%) não são, conforme apresentado na Tabela 1: 
Tabela 1 - Perfil das atletas: idade, tempo de treinamento (TT) e vínculo federativo (VF) na FPB.

\begin{tabular}{|c|c|c|c|}
\hline ATLETA & IDADE & $T T$ & $\begin{array}{c}V F \\
(F P B)\end{array}$ \\
\hline Atleta 1 & 18 anos & 04 anos & SIM \\
\hline Atleta 2 & 13 anos & 08 meses & SIM \\
\hline Atleta 3 & 13 anos & 02 anos & SIM \\
\hline Atleta 4 & 18 anos & 08 anos & SIM \\
\hline Atleta 5 & 12 anos & 03 anos & SIM \\
\hline Atleta 6 & 12 anos & 06 anos & SIM \\
\hline Atleta 7 & 14 anos & 02 anos & SIM \\
\hline Atleta 8 & 13 anos & 01 ano e meio & SIM \\
\hline Atleta 9 & 12 anos & 02 anos & SIM \\
\hline Atleta 10 & 12 anos & 02 anos & SIM \\
\hline Atleta 11 & 11 anos & 03 anos & $\mathrm{NÃO}$ \\
\hline Atleta 12 & 13 anos & 03 anos e meio & SIM \\
\hline Atleta 13 & 17 anos & 06 anos & NÃO \\
\hline TOTAL & 178 & 43,6 anos & - \\
\hline MÉDIA & 13,41 & 3,38 anos & - \\
\hline $\mathbf{D P}$ & $\pm 2,27$ & $\pm 2,2$ & - \\
\hline
\end{tabular}

\section{Resultados e Discussão}

A fim de identificar os conhecimentos das atletas relativos ao referencial histórico-cultural, assim como seu interesse no mesmo, a entrevista foi semiestruturada em três blocos, também utilizados para organizar a apresentação e discussão dos dados, sendo eles:

1. Contexto geral da modalidade (história, regras e manifestações do jogo);

2. Contexto nacional (atletas e títulos mais representativos);

3. Estímulo do técnico ao conhecimento do basquetebol.

Os dados levantados foram poucos, o que já demonstra o pouco conhecimento das jogadoras sobre a modalidade que praticam, como mostram os resultados:

\section{Bloco 1: Contexto Geral da Modalidade}

Nem todas as atletas conseguiram responder a todas as perguntas. Atribuímos isso à falta de conhecimento sobre o assunto. As que tentaram, apresentaram conhecimentos superficiais, equivocados e sem criticidade.

Com relação à história da modalidade, uma delas respondeu: "Pêssegos. Não eram bolas, eram pêssegos, uma cesta de pêssegos. Não sei que 
país que era. Jogavam na cesta, assim, depois que foram modernizando." (Atleta 13)

Ainda no mesmo Bloco, ao ser questionada sobre a compreensão da mudança das regras da modalidade, uma delas respondeu em forma de pergunta: "Porque teve algum problema, né?" (Atleta 6).

\section{Bloco 2: Contexto Nacional}

Quando questionadas sobre os principais títulos das seleções feminina e masculina, uma das atletas, sobre a seleção feminina, respondeu: "Acho que já ganhou alguns títulos, só que eu não lembro o que ganhou." (Atleta 10). E sobre a seleção masculina, outra atleta afirmou: "Acho que nas Olimpíadas ou no Mundial, que o Brasil ganhou dos EUA, mas eu não sei quando." (Atleta 4)

\section{Bloco 3: Estímulo do técnico ao conhecimento do basquetebol}

Questionando sobre o que as atletas aprendem nos treinamentos de basquetebol, tivemos dois grupos com respostas diferentes, sendo um relacionado ao referencial técnico-tático:

Fazer direito senão paga 10. Fazer tudo direito envolve tudo, movimentação, drible, bandeja, arremesso. (Atleta 5)

Treinar, exercícios, treinos mesmo pra fazer os jogos. (Atleta 6)

Defesa. (Atleta 12)

E o outro sobre o referencial socioeducativo:

Mais comprometimento, não é uma coisa que depende só de você. Se uma faz uma coisa errada, as outras vão estar pagando por isso, entendeu? E respeito também. (Atleta 1)

Eu acho que o mais importante que a gente aprende é a disciplina. (Atleta 4)

Vontade. Concentração, o mais certo é a concentração. (Atleta 8)

Porém, não obtivemos nenhuma resposta sobre o referencial histórico-cultural. E para um fechamento sobre os questionamentos feitos, per- 
guntamos se as atletas achavam estes assuntos interessantes e importantes de serem aprendidos nas aulas. Neste momento, tivemos a única participação massificada e convicta:

Ajuda também, porque tipo assim, às vezes tem gente que nem joga basquete e vem perguntar uma coisa pra você fala uma coisa que você nem sabia, daí você não vai saber responder. Daí a pessoa vira e fala pra você: nossa, mas você não joga basquete? Você não sabe disso? (Atleta 1$)$.

Eu aprendo mais (Atleta 5).

Pra gente influencia mais, eu acho. Sente mais vontade de fazer mais coisa. Fica querendo saber mais (Atleta 8).

Os resultados obtidos indicaram o pouco conhecimento das atletas, além de sinalizarem para equívocos e superficialidade em diversas perguntas em relação ao referencial histórico-cultural, bem como para a ausência de estímulos por parte da comissão técnica. Porém, constatamos também motivação e interesse das atletas em adquirir tais conhecimentos, como demonstra a Tabela 2:

Tabela 2: Resultados da Entrevista

\begin{tabular}{|l|l|}
\hline \multicolumn{2}{|c|}{ Dados da Pesquisa } \\
\hline Contexto Histórico & \multicolumn{1}{|c|}{ Bloco: } \\
\hline Pergunta / Tema & Qualidade das Respostas \\
\hline História da modalidade & $\begin{array}{l}\text { Poucas respostas, com informações incompletas e } \\
\text { equivocadas. }\end{array}$ \\
\hline Compreensão das regras & $\begin{array}{l}\text { Conhecimentos básicos, sem compreensão de sua } \\
\text { lógica e evolução. }\end{array}$ \\
\hline \multicolumn{2}{|c|}{$\mathbf{2}^{\mathbf{0}}$ Bloco: } \\
Contexto Nacional \\
$\begin{array}{l}\text { Títulos seleção Masculina e e } \\
\text { Feminina e Atletas de } \\
\text { Destaque }\end{array}$ & $\begin{array}{l}\text { Não sabiam apontar os títulos historicamente } \\
\text { conquistados, tampouco o número significativo de } \\
\text { atletas. }\end{array}$ \\
\hline $\mathbf{3}^{\mathbf{0}}$ Bloco: Estímulo ao conhecimento & \\
\hline Estímulo ao conhecimento & $\begin{array}{l}\text { As respostas foram referentes aos referenciais } \\
\text { técnico-tático e socioeducativo. }\end{array}$ \\
\hline $\begin{array}{l}\text { Importância e interesse dos } \\
\text { temas }\end{array}$ & $\begin{array}{l}\text { Todas as atletas se mostraram favoráveis e } \\
\text { interessadas em que estes temas sejam } \\
\text { incorporados ao currículo de treinamento. }\end{array}$ \\
\hline
\end{tabular}

Pensar a Prática, Goiânia, v. 17, n. 2, p. 414-430, jan./mar. 2014 423 
Em conformidade com os estudos de Galatti, Paes e Darido (2010), e de Darido e Barroso (2009, p. 268), existe certa tendência dentro das propostas tanto de autores, quanto de treinadores em tratar o referencial metodológico: "há uma definição de o que e como ensinar quando os autores retratam a iniciação esportiva como constituída, essencialmente, de modalidades coletivas."

No referencial socioeducativo, percebemos uma ligação com a preocupação de formação de atitudes importantes para o contexto competitivo. Porém, no referencial histórico-cultural, de forma intencional, notamos poucas referências específicas que abordem tal perspectiva de ensino nos treinamentos, o que se comprova através da entrevista realizada, na qual nenhuma das atletas conseguiu responder de forma consciente e correta as perguntas feitas.

Contudo, entre os poucos estudos na literatura, encontramos alguns que sinalizam para a possibilidade do trato pedagógico com o referencial aqui defendido. Machado et al (2011) realizaram uma pesquisa para verificar as aprendizagens adquiridas por adolescentes entre 11 e 15 anos em um projeto social. Os pesquisadores constataram que, além dos aspectos técnicos e táticos e de modos de comportamento, os alunos também identificaram conhecimentos referentes ao processo histórico de diferentes modalidades esportivas, bem como a relação entre esporte e mídia, torcidas organizadas, entre outros assuntos.

A valorização de qualquer modalidade depende diretamente da história que esta percorreu nos cenários nacionais e internacionais, o que está atrelado ao conhecimento sobre os atletas que construíram essa história. O Banco Nacional de Desenvolvimento Econômico e Social (BNDES), em documento sobre a situação atual e propostas de desenvolvimento ao esporte no Brasil, em 1997, indicava, entre outros pontos, a importância de se ter ídolos nas modalidades esportivas, o que contribui para o processo de massificação e formação no esporte. Mas como ter e reconhecer ídolos em uma geração que não foi estimulada a conhecer parte da sua história no contexto esportivo?

Machado, Galatti e Paes (2011) apresentaram diferentes procedimentos pedagógicos que podem ser utilizados pelos professores e técnicos, com a intenção de fortalecer o processo de ensino, vivência e aprendizagem das questões históricas e culturais de modalidades esportivas, dentre os quais destacamos a utilização de pesquisas, vídeos, documentários, bem como a construção de um painel de notícias.

Pensar a Prática, Goiânia, v. 17, n. 2, p. 414-430, jan./mar. 2014 424 


\section{Considerações Finais}

É de notório conhecimento a evolução do fenômeno do esporte na contemporaneidade, sendo necessário que os estudos acerca do fenômeno também avancem. Portanto, é proposto nesta pesquisa um melhor trato prático com um terceiro referencial para abordagens teóricas e práticas, com fundamentação na Pedagogia do Esporte: o histórico-cultural.

Para fortalecer a Pedagogia do Esporte como comprometida com a formação da cidadania e da autonomia, faz-se necessário que professores / técnicos pautem aulas e treinamentos com equilíbrio dos três referenciais apresentados neste estudo. Salientamos que este trabalho pode ser oferecido no cenário da educação não formal, principalmente com alunos ou atletas em idade infanto-juvenil que ainda estão em processo de formação.

Acreditamos que um trabalho pautado nos referenciais técnico-tático, socioeducativo e histórico-cultural possa enriquecer a formação esportiva de futuros atletas profissionais ou amadores, assim como a formação humana através do esporte. Com isso, espera-se contribuir para que crianças e jovens que ingressem no esporte não formal possam ter informação e formação completas, a fim de poderem optar entre as múltiplas possibilidades que o esporte oferece atualmente, como educação, socialização, lazer, representação, profissão, saúde, estética, entre outros, seja no papel de praticantes ou de espectadores.

Levando em consideração que, por vezes, a logística de uso dos espaços para a prática de treinamentos é restrita às instituições promotoras do esporte de base, propomos que técnicos/professores estimulem a busca de informações acerca da modalidade desenvolvida, tanto na mídia como em sites oficiais, tais quais das Federações, Confederações, Comitês Olímpicos, dentre outros.

Sugerimos, ainda, momentos pré ou pós-treinamentos para a troca das informações levantadas, assim como discussão de temas polêmicos, tais quais mudanças nas regras ou comportamento de jogadores.

De maneira mais sistemática, sinalizamos para a construção de um blog didático da equipe, a fim de que técnicos e jogadores possam interagir em ambiente virtual e trocar informações em torno da modalidade que dirigem e praticam, fomentando o convívio com as questões histórico-culturais do esporte.

Por fim, destacamos a necessidade de a comunidade acadêmica dedicada aos estudos em Pedagogia do Esporte divulgar mais estudos relativos aos processos de ensino, vivência a aprendizagem esportiva, estabelecendo interface entre a prática didática e a produção científica.

Pensar a Prática, Goiânia, v. 17, n. 2, p. 414-430, jan./mar. 2014 425 


\title{
SPORT PEDAGOGY AND REFERENTIAL HISTORIC-CULTURAL: DIA- LOGUE BETWEEN THEORY AND PRACTICE
}

\begin{abstract}
he Sport Pedagogy notes sport while a sociocultural phenomenon, defending its teaching from three perspectives: technical-tactical, socio-educational and historiccultural, the latter being the focus of this study. Thus, it presents the results and analysis of field research with a female basketball team tied to São Paulo Basketball Federation in order to highlight the mistreatment of historical-cultural aspects of sport classes and sports training. After that, it signs pedagogical practices that can contribute to better approach this framework, which can contribute to the expansion of the sports culture of the athlete, student and informal sportsmen.

Keywords: Sport. Sport Pedagogy. Sport Culture. Collective Sports. Basketball.

\section{PEDAGOGÍA DEPORTE Y REFERENCIAL HISTÓRICO-CULTURAL: EL DIÁLOGO ENTRE LA TEORÍA Y LA PRÁCTICA}

\section{Resumen}

La pedagogía del deporte comprende el deporte como un fenómeno sociocultural, señalando su enseñanza desde tres punto de perspectiva: técnico-táctico, socio-afectivo histórico-cultural, siendo este último el enfoque de esta investigación. Por lo tanto, se presentan los resultados y análisis de la investigación de campo con un equipo de baloncesto femenino vinculado a la Federación de Baloncesto de São Paulo con el fin de poner de relieve el maltrato de los aspectos histórico-culturales en las clases de deporte y entrenamiento deportivo. En la secuencia, señala posibles prácticas pedagógicas que pueden contribuir a un mejor enfoque de este marco, lo que puede fomentar a la expansión de la cultura deportiva del atleta, estudiante y practicante informal.

Palabras-claves: Deporte. Pedagogía del Deporte. Cultura Deporte. Juegos Colectivo Deportes. Baloncesto.

\section{Referências}

BANCO NACIONAL DE DESENVOLVIMENTO ECONÔMICO E SOCIAL (BNDES). Esporte no Brasil: situação atual e propostas para o desenvolvimento. $\quad$ Brasil, $1997 . \quad$ Disponível em: http://www.bndes.gov.br/conhecimento/relato/esprt-br.pdf Acesso em: 13 de setembro de 2010. 
BARROSO, A. L. R.; DARIDO, S. C.: A Pedagogia do Esporte e as Dimensões dos Conteúdos: Conceitual, Procedimental e Atitudinal. Revista da Educação Física /UEM. Maringá, v. 20, nº 2, p. 281 - 289, $2^{\circ}$ trim, 2009.

BUNKER; THORPE. (1986) The curriculum model. Rethinking Games Teaching, Loughborough University Of Technology, n. , p.7-10, 05 out. 1986.

Disponível em: $<$ http://www.educ.uvic.ca/Faculty/thopper/index.htm>. Acesso em: 25 maio 2011

BAYER, C. O ensino dos jogos desportivos colectivos. Paris: Vigot, 1994.

DELORS, J. Educação um tesouro a descobrir. Relatório para a Unesco da Comissão Internacional sobre a Educação para o Século XXI. 6. ed. Tradução José Carlos Eufrázio. São Paulo: Cortez, 2001.

DIETRICH, $\mathrm{K}$ et al. Os grandes jogos: metodologia e prática. Rio de Janeiro: Ao Livro Técnico S/A, 1984.

FREIRE, J.B. Educação de corpo inteiro: teoria e prática da educação física. $4^{a}$ ed. São Paulo: Scipione, 2002.

FREIRE, J.B., SCAGLIA, A.J: Educação como prática corporal. São Paulo, Scipione, 2003.

GALATTI, L. R.: Pedagogia do esporte: o livro didático como mediador no processo de ensino e aprendizagem dos jogos esportivos coletivos. 2006. Dissertação (Mestrado em Educação Física) - Faculdade de Educação Física, Universidade Estadual de Campinas, Campinas, 2006.

GALATTI, L. R. ; Paes, R. R.; MONTERO SEOANE, A. ; Balbino, H.F. ; FERREIRA, H. B. ; SILVA, Y. P. G. . Clube Esportivo e Iniciação em Basquetebol: os recursos didáticos escritos como fomentadores do esporte e do clube.. In: II Congreso Internacional de Deportes de Equipo, 2009, A Coruña. II Congreso de Deportes de Equipo, 2009.

GALATTI, L.R., PAES, R.R., DARIDO, S.C. Pedagogia do Esporte: livro didático aplicado aos Jogos Esportivos Coletivos. Motriz: Revista de Educação Física, v.16, p.751 - 761, 2010.

GRAÇA, A.; OLIVEIRA, J. (Coords). O ensino dos jogos desportivos, 2ed. Porto: Universidade do Porto, 1995. 
GRECO, P. R., BENDA, R. N. (org.) Iniciação Esportiva Universal: da aprendizagem motora ao treinamento técnico. Belo Horizonte: UFMG, $2^{\mathrm{a}}$ reimpressão, 2007.

GRECO, P. J. et al. Iniciação Esportiva Universal - Volume 2. Belo Horizonte: Editora Universitária - UFMG, 1998.

HIRAMA, L.: Algo para além de tirar as crianças da rua: A Pedagogia do Esporte em Projetos socioeducativos. 2008. Dissertação (Mestrado em Educação Física) - Faculdade de Educação Física, Universidade Estadual de Campinas, Campinas, 2008.

LEITÃO, B. J. M.: Grupos de foco: o uso da metodologia de avaliação qualitativa como suporte complementar à avaliação qualitativa realizada pelo Sistema de Bibliotecas da USP. 2003. Dissertação (Mestrado em Ciências da Comunicação) - Faculdade de Ciências da Comunicação, Universidade de São Paulo, USP, 2003.

MACHADO, G.V.; et al: A sistematização de conteúdos na educação não formal. In: IV Congresso Internacional de Ciência do Desporto - III Simpósio Internacional de Ciência do Desporto. Unicamp, 2011.

MACHADO, G.V.; GALATTI, L.R.; PAES, R.R.: Seleção de conteúdos e procedimentos pedagógicos para o ensino do esporte em projetos sociais: reflexões a partir dos jogos esportivos coletivos. Motrivivência, Ano XXIV, No 39, P. 164-176 Dez./2012.

MACHADO, G.V.: Pedagogia do Esporte: organização, sistematização, aplicação e avaliação de conteúdos esportivos na educação não formal. 2012. Dissertação (Mestrado em Educação Física) - Faculdade de Educação Física, Universidade Estadual de Campinas, Campinas, 2012.

MORGAN, D. L: Focus Groups. Annual Review Sociology, n 22, p. $129-$ 152, 1996. In LEITÃO, B. J. M.: Grupos de foco: o uso da metodologia de avaliação qualitativa como suporte complementar à avaliação qualitativa realizada pelo Sistema de Bibliotecas da USP. 2003. Dissertação (Mestrado em Ciências da Comunicação) - Faculdade de Ciências da Comunicação, Universidade de São Paulo, USP, 2003. 
PAES, R. R.: Educação Física Escolar: o Esporte como conteúdo pedagógico no Ensino Fundamental. 1996. Tese (Doutorado em Educação Física). Faculdade de Educação Física, Universidade Estadual de Campinas, Campinas, 1996.

PAES, R. R., BALBINO, H. F. A pedagogia do esporte e o jogos coletivos. Cap. 5 , p. 73 - 83. In: DE ROSE, D. et al. Esporte na Infância e Adolescência: uma abordagem multidisciplinar. $2^{\mathrm{a}}$ Ed. Porto Alegre: Artmed, 2009.

PAES; R.R.; GALATTI, L.R.: Pedagogia do Esporte: o clube sócio-esportivo como uma nova possibilidade de ambiente. In: TANI, G.; et al: Celebrar a lusofonia: ensaios e estudos do desporto e Educação Física. Cap.18, p. $421-460,2002$.

PAES; R.R.; GALATTI, L.R: Pedagogia do Esporte: o esporte educacional no contexto do clube contemporâneo. In: GONÇALVES, C.E.B. Educação pelo Desporte e Associativismo Desportivo. Porto: Edições Afrontamento, P.85-110, 2003.

REVERDITO, R. S.; SCAGLIA, A. J.: Pedagogia do Esporte: Jogos Coletivos de Invasão. São Paulo, Phorte, 2009.

SANTANA, W. A pedagogia do Esporte na infância e complexidade. In PAES, R. e BALBINO, H.: A Pedagogia do Esporte: Contextos e Perspectivas. Rio de Janeiro: Guanabara Koogan, p: 1-22, 2005.

SIEDENTORP, D. Sport Education: Quality PE through positive sport experiences. Champaign, IL: Human Kinetics, 2003.

Recebido em: 03/06/2013

Revisado em: 21/08/2013

Aprovado em: 26/11/2013

Endereço para correspondência:

giseleviola_ef@yahoo.com.br

Gisele Viola Machado

Universidade Estadual de Campinas, Faculdade de Educação Física, Departamento de Educação Física e Humanidades.

Cidade Universitária Zeferino Vaz 
Barão Geraldo

13083970 - Campinas, SP - Brasil

Pensar a Prática, Goiânia, v. 17, n. 2, p. 414-430, jan./mar. 2014 